\title{
Spatial Variability of Snow Density and Its Estimation in Different Periods of Snow Season in the Middle Tianshan Mountains, China
}

\author{
Ting FENG ${ }^{1}$, Shuzhen Zhu ${ }^{1}$, Farong Huang ${ }^{1}$, Jiansheng $\mathrm{Hao}^{2}$, Richard Mind'je ${ }^{1}$, Jiudan \\ Zhang ${ }^{1}$, and Lanhai $\mathrm{Li}^{1}$ \\ ${ }^{1}$ Chinese Academy of Sciences \\ ${ }^{2}$ Institute of Geographic Sciences and Natural Resources Research CAS
}

September 27, 2021

\begin{abstract}
Snow density is one of the essential properties to describe snowpack characteristics. To obtain the spatial variability of snow density and estimate it accurately in different periods of snow season still remain as challenges, particularly in the mountains. This study analyzed the spatial variability of snow density with in-situ measurements in three different periods (i.e. accumulation, stable, melt period) of snow seasons 2017/2018 and 2018/2019 in the middle Tianshan Mountains, China. The performance of multiple linear regression model (MLR) and three machine learning models (i.e. Random Forest (RF), Extreme Gradient Boosting (XGB) and Light Gradient Boosting Machine (LGBM)) to simulate snow density has been evaluated. It was found that the snow density in melt period $(0.27 \mathrm{~g} \mathrm{~cm}-3)$ was generally greater than that in stable $(0.20 \mathrm{~g} \mathrm{~cm}-3)$ and accumulation period $(0.18 \mathrm{~g} \mathrm{~cm}-3)$, and the spatial variability of snow density in melt period was slightly smaller than that in other two periods. The snow density in mountainous areas was generally higher than that in plain or valley areas, and snow density increased significantly $(\mathrm{p}<0.05)$ with elevation in the accumulation and stable periods. Besides elevation, latitude and ground surface temperature also had critical impacts on the spatial variability of snow density in the middle Tianshan Mountains, China. In this work, the machine learning model, especially RF model, performed better than MLR on snow density simulation in three periods. Compared with MLR, the determination coefficients of RF promoted to $0.61,0.51$ and 0.58 from 0.50, 0.1 and 0.52 in accumulation period, stable period and melt period respectively. This study provide a more accurate snow density simulation method for estimating regional snow mass and snow water equivalent, which allows us to achieve a better understanding of regional snow resources.
\end{abstract}

\section{Hydrological Processes}

Subject: Novelty and international appeal statement

Snow density is one of the most important and fundamental physical properties of snow, it is a critical measure used to convert snow depth to snow water equivalent, so it plays a crucial role in mountainous hydrological process. However, it is very difficult to obtain snow density data in a large space scale, especially in mountainous area. In this work, we conducted six snow cover surveys to obtain the spatial distribution of snow density in Tianshan Mountains of China in different periods of snow season. We also provided a more accurate method to estimate snow density by compared the accuracy of snow density simulation with multiple linear regression model and three machine learning models. This study will help to improve the understanding of spatial distribution of snow density in mountainous regions with continental snow climate, provide theoretical support for better simulation of snow density and lead to better understanding of hydrological process in mountainous area.

Ting Feng 


\section{Hosted file}

02Title Page.docx available at https://authorea.com/users/438083/articles/539359-spatialvariability-of-snow-density-and-its-estimation-in-different-periods-of-snow-season-inthe-middle-tianshan-mountains-china

\section{Hosted file}

03Main Text.docx available at https://authorea.com/users/438083/articles/539359-spatialvariability-of-snow-density-and-its-estimation-in-different-periods-of-snow-season-inthe-middle-tianshan-mountains-china
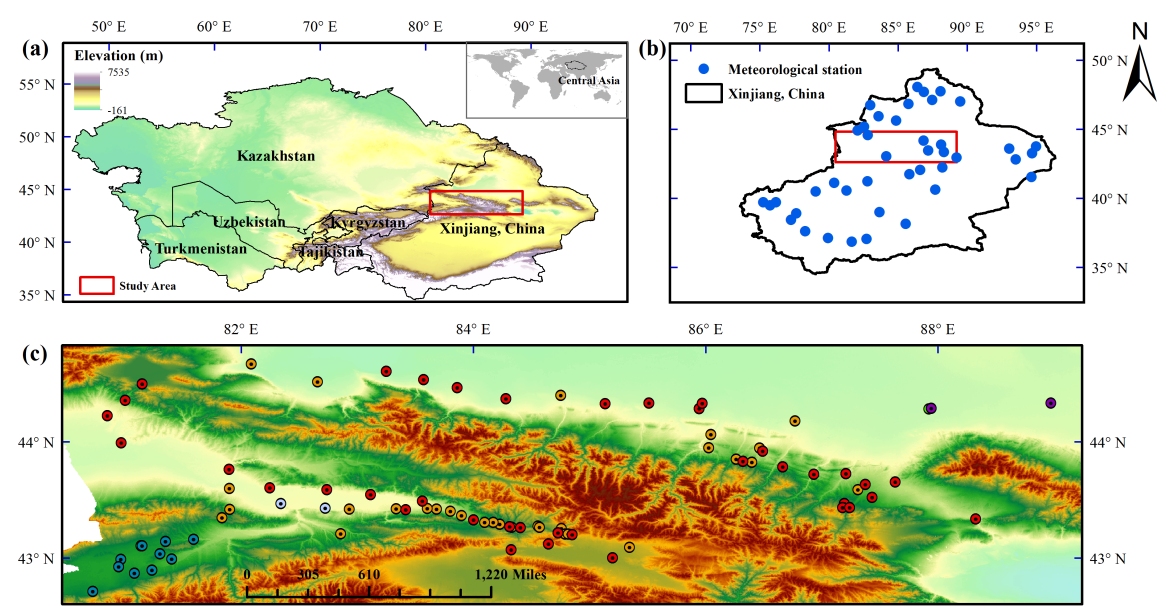

(d)
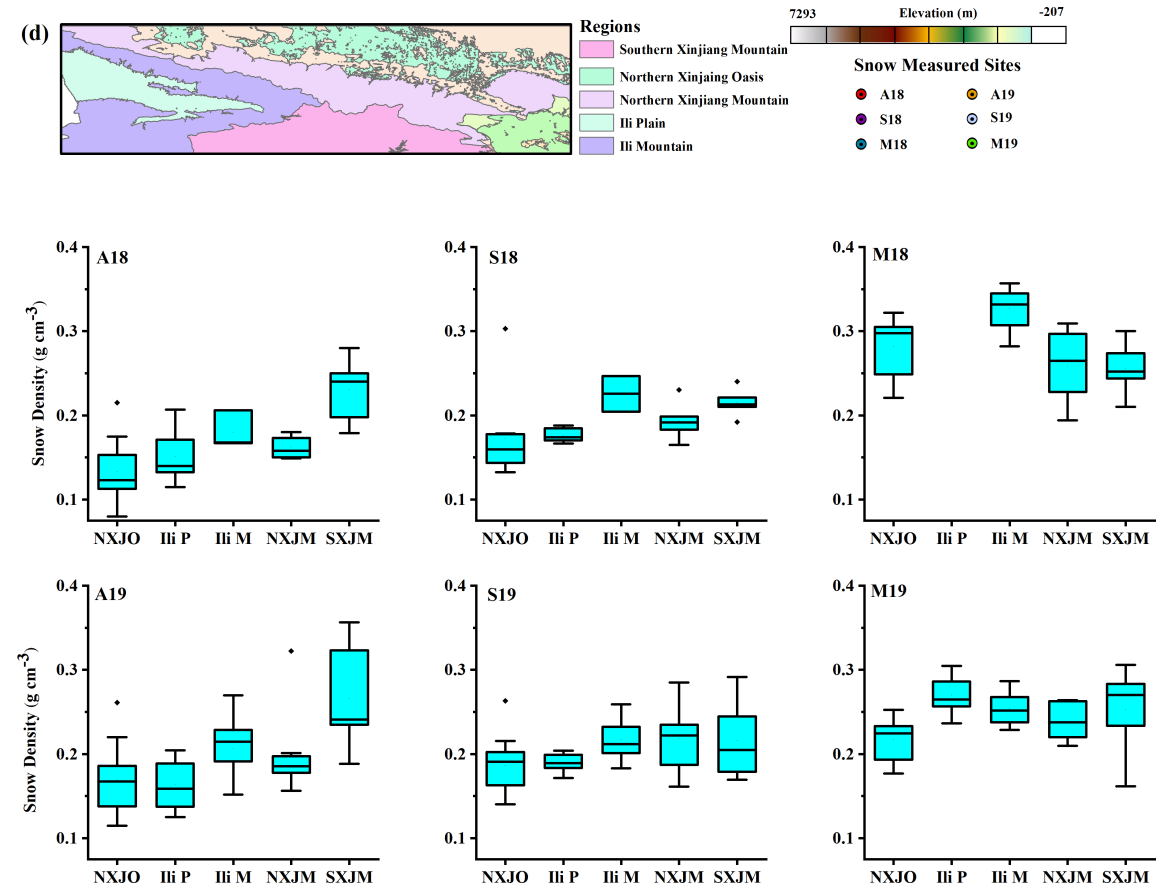

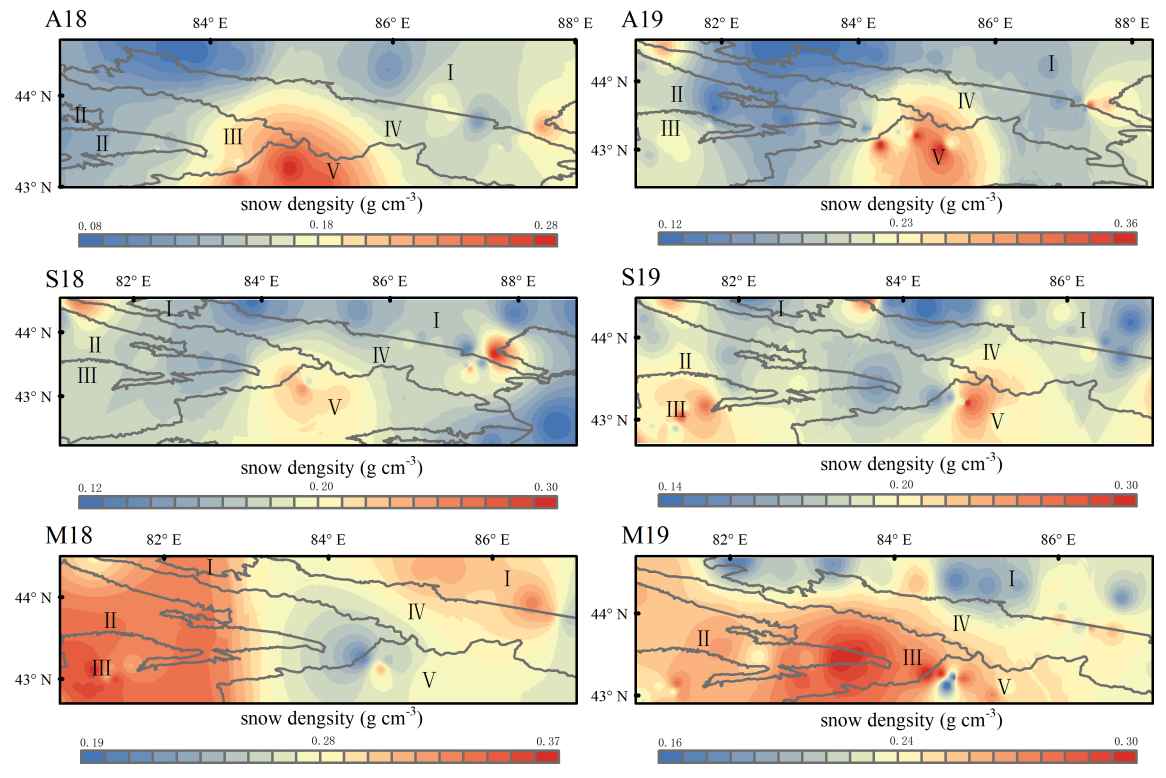

\begin{tabular}{llllllll} 
& A18 & S18 & M18 & A19 & S19 & M19 \\
ALL & 0.31 & 0.19 & 0.15 & 0.27 & 0.16 & 0.14 \\
\hline NXJM & 0.08 & 0.11 & 0.19 & 0.26 & 0.18 & 0.09 \\
\hline NXJO & 0.29 & 0.28 & 0.14 & 0.21 & 0.16 & 0.11 \\
\hline Ili M & 0.12 & 0.13 & 0.07 & 0.16 & 0.10 & 0.08 \\
Ili P & 0.21 & 0.05 & $/$ & 0.17 & 0.06 & 0.08 \\
\hline SXJM & 0.15 & 0.08 & 0.13 & 0.21 & 0.20 & 0.21 \\
& & & & & & \\
\hline & $\mathbf{0 . 3 3}$ & & & & & $\mathbf{0 . 0 5}$
\end{tabular}


(a)

$\begin{array}{ccccccc} & \text { Elv } & \text { Lon } & \text { Lat } & \text { slope } & \text { LS_ct } & S D \\ \text { A18 } & \mathbf{0 . 7 9} & -0.03 & -\mathbf{0 . 6 1} & 0.31 & -0.27 & \mathbf{0 . 4} \\ \text { S18 } & \mathbf{0 . 5 6} & -0.19 & -0.03 & 0.32 & -0.05 & 0.22 \\ \text { M18 } & -0.1 & -\mathbf{0 . 6 7} & -0.29 & -0.19 & 0.24 & -0.1 \\ \text { A19 } & \mathbf{0 . 7 6} & 0.08 & -\mathbf{0 . 4 5} & \mathbf{0 . 2 6} & -0.12 & \mathbf{0 . 3 8} \\ \text { S19 } & \mathbf{0 . 4 8} & -0.06 & -\mathbf{0 . 3 8} & \mathbf{0 . 3 9} & 0.1 & 0.21 \\ \text { M19 } & 0.23 & -0.23 & \mathbf{- 0 . 4 4} & 0.06 & -0.16 & \mathbf{0 . 3}\end{array}$

(b)

\begin{tabular}{|c|c|c|c|c|c|c|}
\hline & $G S T$ & TEM & $P R S$ & $S S D$ & RHU & $W I N$ \\
\hline A18 & -0.6 & -0.4 & -0.54 & 0.5 & -0.69 & -0.21 \\
\hline S18 & -0.13 & -0.25 & -0.34 & 0.22 & -0.06 & 0.09 \\
\hline M18 & 0.62 & 0.56 & 0.34 & -0.59 & 0.21 & -0.69 \\
\hline A19 & -0.32 & -0.37 & -0.39 & 0.46 & -0.08 & -0.5 \\
\hline S19 & 0.31 & 0.21 & 0.23 & 0.18 & -0.18 & 0.02 \\
\hline M19 & -0.2 & -0.16 & -0.24 & 0.37 & -0.26 & 0.27 \\
\hline
\end{tabular}
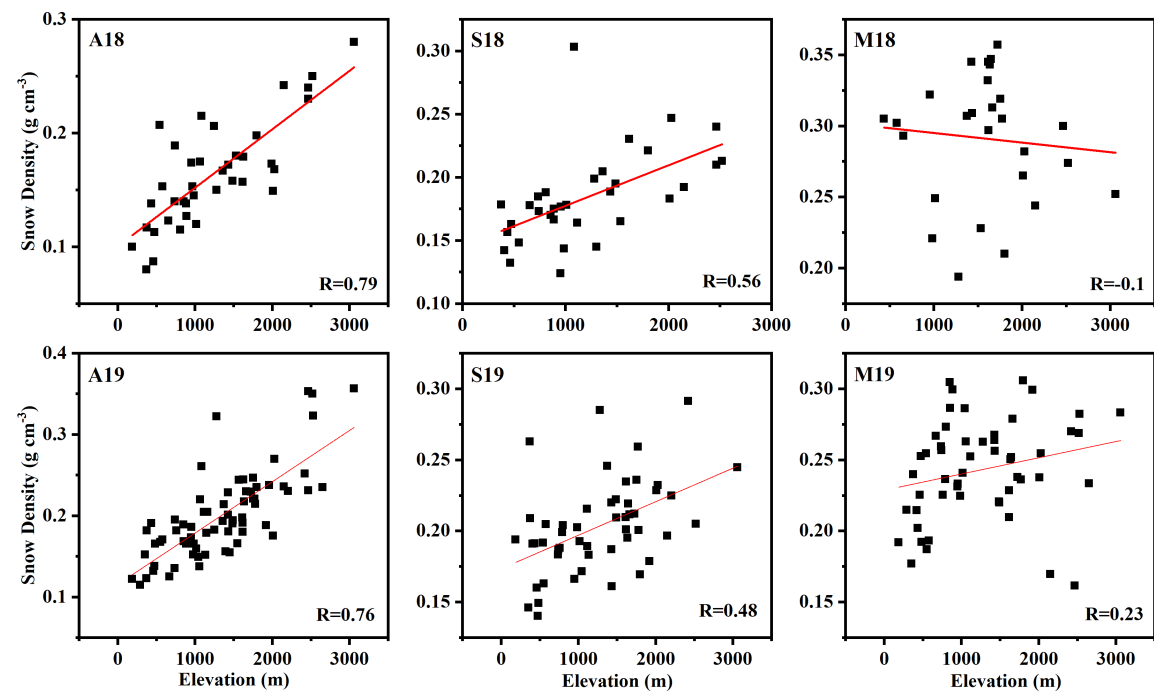

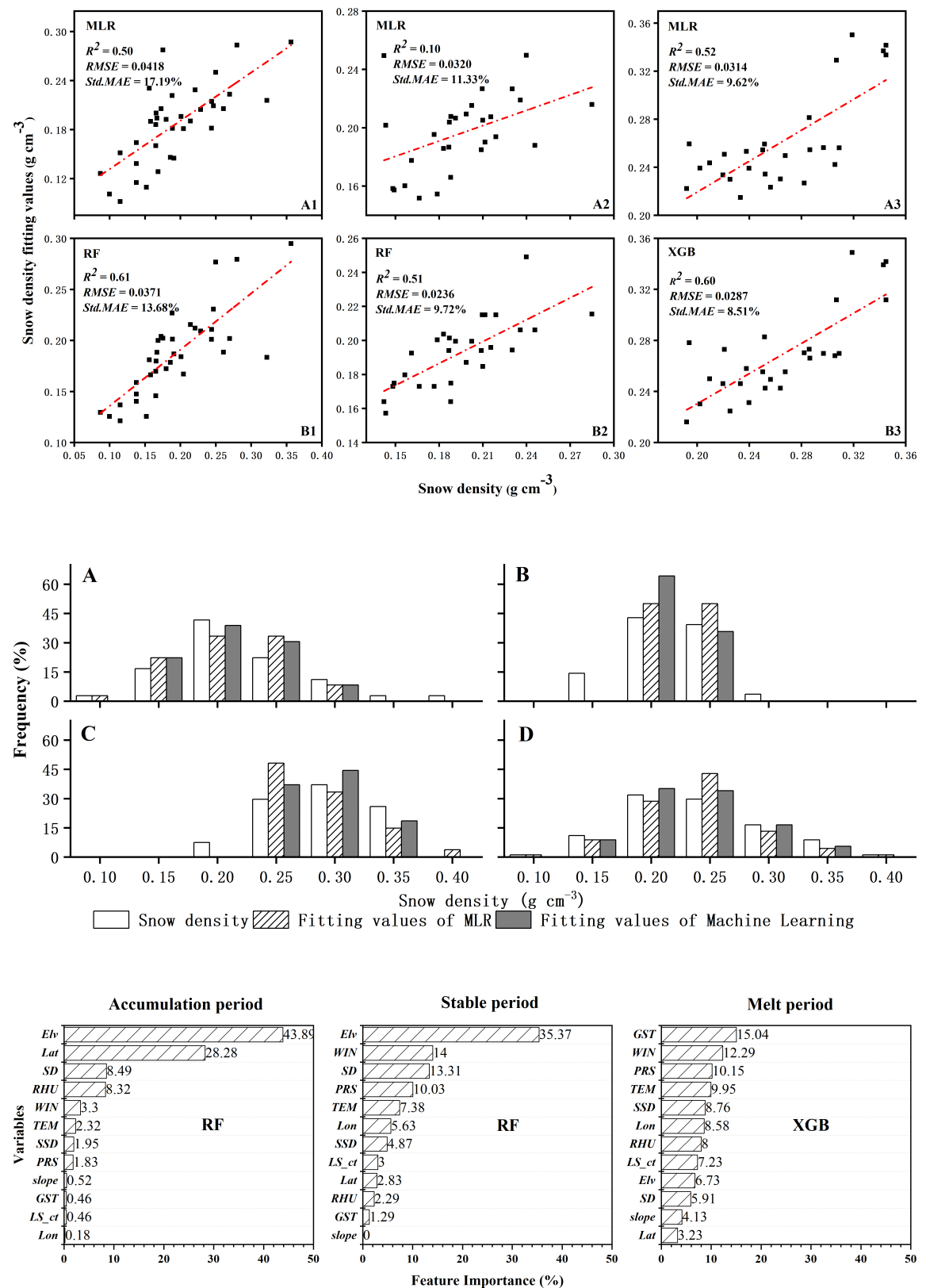